\title{
Course of buccal nerve on the anterior border of mandibular ramus related to temporalis tendon
}

\author{
Heung-Joong Kim ${ }^{1,2}$, Byung Soo Park ${ }^{1}$, Yonghwa Cho ${ }^{1}$, and Sun-Kyoung Yu ${ }^{1,2 *}$ \\ ${ }^{1}$ Department of Oral Anatomy, College of Dentistry, Chosun University, Gwangju 61452, Republic of Korea \\ ${ }^{2}$ Oral Biology Research Institute, Chosun University, Gwangju 61452, Republic of Korea
}

(Received Aug 18, 2017; Revised version received Sep 7, 2017; Accepted Sep 7, 2017)

\begin{abstract}
The purpose of this study was to examine the course of the buccal nerve on the anterior border of mandibular ramus in relation to superficial and deep tendons of the temporalis muscle. Distance was measured from the lingula level to each of the two points where the buccal nerve crosses over the deep tendon on the lingual side and the superficial tendon on the buccal side. The buccal nerve crossed over the deep tendon at approximately $2.4 \mathrm{~cm}$ above the lingula level and descended infero-laterally over the superficial tendon at approximately $0.2 \mathrm{~cm}$ above the lingula level towards the buccal side. In a dentulous adult, lingula is located approximately $1 \mathrm{~cm}$ above the occlusal plane. Therefore, when making incisions on the mandibular ramus beyond the occlusal plane, clinicians must be careful because the buccal nerve and temporalis tendons can be damaged.
\end{abstract}

KEY WORDS: Buccal nerve, Mandibular ramus, Temporalis tendon, Lingula

\section{서 론}

볼신경(buccal nerve)은 긴볼신경(long buccal nerve)이라 고도 불리는데, 이는 신경의 경로가 매우 길고 다양하기 때 문이다. 이 신경은 아래턱신경의 앞줄기에서 분지하여 가 쪽날개근의 두갈래 사이에서 나와, 관자근(temporalis muscle) 닿는곳(insertion)과 턱뼈가지(mandibular ramus) 앞 모서리(anterior border)를 교차하여, 볼의 가쪽을 지나 볼근 을 뜷고 입꼬리까지 매우 긴 경로를 가진다[1-3]. 이러한 볼 신경은 인접한 피부와 입안 점막 및 아래턱 어금니의 볼쪽 잇몸에 분포하는 감각신경과 가쪽날개근과 관자근 일부를 지배하는 운동신경을 포함한다[2, 4]. 이러한 긴 경로와 넓 은 분포 범위에도 불구하고, 아래턱 시술 동안 손상의 가능 성이 적고 손상 후 합병증에 대한 보고가 적어 임상의들에 게 이 신경에 대한 주의가 부족하였다[5,6]. 그러나 최근 턱빼가지가 골이식 시 공여부위로 제공되고 더불어 매복치

*Corresponding author: Sun-Kyoung Yu

Department of Oral Anatomy, College of Dentistry, Chosun University, 309 Pilmun-daero, Dong-gu, Gwangju 61452, Republic of Korea Tel.: +82-62-230-6357, Fax: +82-62-224-3706

E-mail: sky@chosun.ac.kr
발치 및 턱관절 정복술 시 볼신경의 손상 가능성 증가로 그 중요성이 다시 대두되고 있다[3,7].

관자근은 아래관자근선과 관자오목에서 일어나 근육돌 기(coronoid process)에 닿는 단일 층의 입을 닫는 근육 그 룹(폐구근)의 하나로 알려져 있으나[1], 안쪽에서 나비뼈 큰날개의 아래관자능선에서 일어나 수직으로 내려와 아래 턱뼈의 관자능선(temporal crest)에 닿는 깊은 다발과 바깥 쪽의 부채꼴로 근육돌기와 턱뼈가지의 앞모서리를 따라 부착하는 얕은 다발의 두층으로 나뉜다는 보고가 꾸준히 있다 $[4,8,9]$. 특히 이러한 두층의 근육 다발은 닿는곳에서 깊은 다발은 깊은힘줄(deep tendon)이 되어 어금니뒤삼각 (retromolar triangle)의 안쪽 경계를 이루고, 얕은 다발은 얕은힘줄(superficial tendon)이 되어 바깥쪽 경계를 이룬다 $[4,7,8]$. 관자근 힘줄에 관한 이러한 형태학적 보고가 있고 어금니뒤삼각 부위의 외과적 시술이 증가하는데 반하여, 여전히 이 부위를 교차하여 지나가는 볼신경의 경로에 관 한 연구가 거의 없다.

따라서 본 연구에서는 턱뼈가지 안쪽면에서 나와 바깥 쪽의 볼근을 향하여 주행하는 볼신경이 특히 관자근의 깊 은힘줄과 얕은힘줄을 교차하는 두 지점에서 골격적 표지 점으로부터의 거리를 계측하여 그 경로를 자세히 살펴보 고자 하였다. 


\section{재료 및 방법}

본 연구는 조선대학교 의과대학 해부학교실에 교육용 목적으로 기증된 시신 26 구에서 학생 실습이 완료된 이후, 관자근과 볼신경이 손상 없이 온전히 남아 있는 아래턱 14쪽(오른쪽 6쪽, 왼쪽 8쪽)에서 의학 연구 및 윤리에 관 한 헬싱키 선언에 따라 이루어졌다. 볼신경이 분석된 시신 은 남자 12 구와 여자 2 구였으며, 사망 시 나이는 40 세에서 84세로 평균 60.5 세였다. 특히 이들은 모두 자연치아 그대 로 또는 치과치료를 통해 어금니를 가지고 있는 분을 선 택하였는데, 이는 치아 상실 후 어금니뒤 부위의 이틀뼈와 관자근 닿는곳의 형태 변화로 볼신경의 경로에 영향이 일 어날 수 있는 경우는 제외하고자 하였다.

턱뼈가지 안쪽면에서 나와 바깥쪽의 볼근을 향하여 주 행하는 볼신경이 특히 관자근 닿는곳 부위에서 교차하여

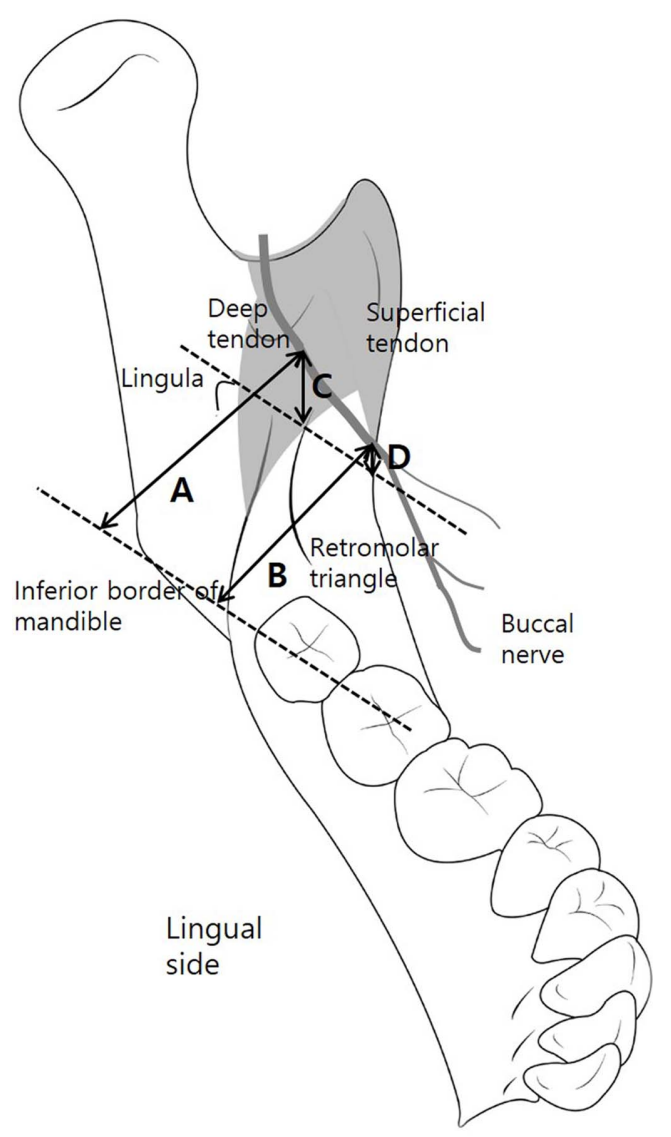

Fig. 1. Diagram showing the parameters of the course of the buccal nerve. A: distance from the inferior border of the mandible to point where buccal nerve crosses over the deep tendon, B: distance from the inferior border of the mandible to point where buccal nerve crosses over the superficial tendon, $\mathrm{C}$ : distance from the lingula level to point where buccal nerve crosses over the deep tendon, D: distance from the lingula level to point where buccal nerve crosses over the superficial tendon.
지나가는 경로를 관찰하기 위하여, 수술용 미세현미경 (OPMI-FC, Carl Zeiss, Oberkochen, Germany)을 이용하여 어금니뒤삼각의 연조직(어금니뒤뭉치, retromolar pad)을 조심스럽게 제거하여 관자근 힘줄과 볼신경을 해부하였다. 이후 볼신경이 턱뼈가지 앞모서리의 안쪽면에 정지하는 관자근의 깊은힘줄과 바깥쪽면에 정지하는 얕은힘줄을 교 차하여 지나가는 각각의 두 지점에서 아래턱빼 아래모서 리(inferior border of mandible)와 혀돌기(lingula) 높이의 수평 연장선으로 부터의 수직 거리를 디지털 캘리퍼 (Mitutoyo, Kawasaki, Japan)를 이용하여 계측하였다(Fig. 1).

모든 계측은 두 명의 관찰자가 동일한 기준에 의하여 다른 날에 2회 반복 측정한 후, IBM SPSS Statistics(version 23.0, IBM Corporation, Somers, NY, USA)을 이용하여 통 계분석을 하였다. 일원배치 분산분석(one-way ANOVA)을 이용하여 관찰자 내, 관찰자 간, 기준선에 따른 두 지점 간, 및 각 계측 항목의 좌우 차이를 유의수준 0.05 에서 통계 분석하였다. 성별과 연령에 따른 차이는 통계 분석을 시행 하지 않았다.

\section{결 과}

관찰된 볼신경은 대부분 관자근 근막 위에서 깊은힘줄 위를 교차하여 어금니뒤삼각을 가로질러 얕은힘줄 아래에

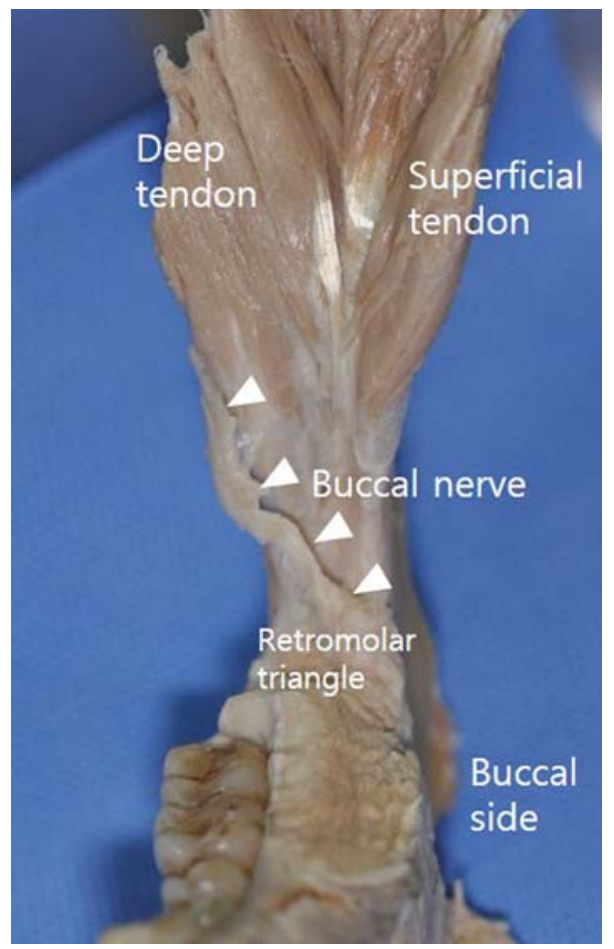

Fig. 2. Photograph of the buccal nerve on the anterior border of mandibular ramus from an anterior view. The white triangles show that the buccal nerve crosses over the temporalis tendons. 
Heung-Joong Kim et al.

Table 1. Distance of the buccal nerve at two points intersecting the inner deep tendon and the outer superficial tendon

\begin{tabular}{lccc}
\hline & Minimum & Maximum & Mean \pm SD \\
\hline To point across deep tendon from inferior border of manidble & 5.08 & 8.05 & $6.10 \pm 0.76$ \\
To point across superficial tendon from inferior border of mandible & 2.60 & 5.73 & $3.81 \pm 0.83$ \\
To point across deep tendon from lingula level & 1.53 & 3.63 & $2.37 \pm 0.57$ \\
To point across superficial tendon from lingula level & -0.78 & 1.43 & $0.20 \pm 0.62$ \\
\hline
\end{tabular}

The unit presents in centimeter $(\mathrm{cm})$.

서 볼쪽으로 향하였으며, 신경이 안쪽 깊은힘줄을 통과하 여 뜷고 지나가는 경우는 단 한쪽에서만 관찰되었다(Fig. 2). 볼신경은 혀돌기 높이의 연장선을 기준으로하여 위쪽 $2.37 \pm 0.57 \mathrm{~cm}$ 에서 아래가쪽으로 가로질러 혀돌기 높이 위 쪽 $0.20 \pm 0.62 \mathrm{~cm}$ 에서 볼쪽으로 주행하였다. 아래턱뼈 아 래모서리를 기준선으로부터 안쪽 깊은힘줄을 교차하는 지 점까지의 평균 거리는 $6.10 \pm 0.76 \mathrm{~cm}$ 였고, 바깥쪽 얕은힘 줄을 지나가는 지점까지의 평균 거리는 $3.81 \pm 0.83 \mathrm{~cm}$ 였다 (Table 1). 아래턱뼈 아래모서리에서 혀돌기까지의 평균 거 리는 $3.61 \pm 0.67 \mathrm{~cm}$ 였다. 각각의 기준선에 따른 안쪽과 바 깥쪽의 두 지점에서의 높이는 유의적으로 차이가 있었으 며 $(p<0.05)$, 각 계측 항목의 좌우 계측값은 모두 유의적으 로 차이가 없었다 $(p>0.05)$.

\section{고 찰}

볼신경은 귀구슬에서 볼굴대를 이은 가상선의 주로 아 래쪽 볼의 피부와 입안 점막에 감각섬유를 내므로 만약 이 러한 신경이 손상되면, 환자는 입안뜰(oral vestibule)에 반 복적으로 음식물이 저류하여 일종의 "finger sweeps"를 호 소하기도 하고 남성의 경우에는 면도 시 지속적인 피부 열 상의 문제가 발생할 수 있다[3,7]. 또한 아래이틀신경 전 달 마취 시 불완전 마취의 원인 중 하나로 볼신경의 가능 성이 제기되었다[10,11]. 이에 최근 볼신경의 경로와 분포 에 관한 연구에 따르면 볼신경이 기존의 분포 영역을 넘 어 뒤쪽으로 목구멍까지, 그리고 앞쪽으로는 입꼬리 위쪽 에서 눈확아래신경과 아래턱 작은어금니 부위에서 턱끝신 경과 다발을 이루며 넓은 분포 영역을 가지므로 그 손상 에 대한 주의가 더욱 강조되고 있다 [3,12].

아래턱 치과 치료 시 턱뼈가지 앞모서리 부위는 매복치 발치, 턱관절 정복술 및 골이식술과 같은 외과적 시술이 이루어져, 치료 시 이 부위를 교차하여 지나가는 볼신경의 손상 위험이 증가한다. 그러나 최근 연구는 분포 영역에 집중하여 그 경로가 조사되어 있어 교차 부위에 대한 이 전 문헌의 기술이 부족하다[3,12]. 즉 이전 연구에 따르면 볼신경은 관자근의 안쪽에서 아래로 내려가거나 또는 근 육을 통과하여 바깥쪽의 얕은힘줄을 지나간다고만 되어
있어 $[8,13]$, 예측 가능한 표지점을 이용하여 그 경로에 대 한 자세한 설명이 필요하다.

Takezawa 등[12]은 사람 태아 90 명의 조직 표본을 분석 하였는데, 이들에 따르면 $49 \%$ 에서 볼신경이 관자근 깊은 힘줄 안쪽을 지나가고, $40 \%$ 에서는 이 힘줄을 통과하여 볼 쪽으로 향한다고 되어 있다. 또한 Harn과 Sjackelford[13] 는 볼신경이 위안쪽에서 깊은힘줄을 지나 아래가쪽으로 얕은힘줄을 지나 볼쪽으로 향한다고 하였다. 본 연구에서 는 볼신경은 대부분 관자근 근막 위에서 깊은힘줄 위를 교 차하여 어금니뒤삼각을 가로질러 얕은힘줄 아래에서 볼쪽 으로 향하였으며, 신경이 관자근을 통과하여 뚫고 지나가 는 경우는 단 한쪽에서만 관찰되었다. 따라서 어금니뒤삼 각에서의 절개선은 볼신경을 손상시킬 수 있으며, 관자근 의 닿는곳이 턱뼈가지 앞모서리와 관자능선을 따라 내려 오면서 그 경계를 형성하므로 치료 시 관자근 힘줄도 함 께 손상될 수 있다. 또한 볼신경이 근육을 통과하여 지나 가는 경우에는 신경이 근육에 포착(entrapment)되어 씹기 와 같은 관자근의 움직임 동안 비특이적 양상의 통증과 감 각이상이 발생할 수 있다. 그러나 본 연구의 표본 수가 부 족하고, 특히 모든 표본에서 관자근 힘줄이 근육돌기를 넘 어 다른 두 부위에서 정지하고 있어 볼신경과 더불어 한 국인에서 이에 관한 추가 연구를 한 필요가 있겠다.

턱뼈가지 안쪽면을 따라 주행하는 혀신경에 대한 주의 로 보통 볼쪽에서 절개선이 이루어지는데, 이에 따라 Heady 등[5]은 볼신경이 바깥빗선(external oblique ridge) 의 가장 깊은 오목에서 7 12 $\mathrm{mm}$ 범위를 가지며 평균 $3 \mathrm{~mm}$ 아래에서 교차하여 지나가므로 절개 시 그 지점까지 닿지 말라고 기술하였다. 그러나 이들의 연구가 무치악에 서 이루어지고 계측 기준점이 다소 모호하여 유치악의 환 자에서 정확한 수치를 이용하기에 어려움이 있다. 본 연구 에서 볼신경은 아래턱뼈 아래모서리에서 $6 \mathrm{~cm}$ 혀돌기 높이 에서 $2.4 \mathrm{~cm}$ 의 위안쪽 지점에서 깊은힘줄을 교차하여 아래 가쪽으로 내려와 아래턱뼈 아래모서리 $3.8 \mathrm{~cm}$ 혀돌기 높이 $0.2 \mathrm{~cm}$ 지점에서 얕은힘줄을 지나 볼쪽으로 향하였다.

결론적으로 유치악의 성인 환자에서 교합평면 약 $1 \mathrm{~cm}$ 위에 혀돌기가 위치하고 바깥쪽 관자근 얕은힘줄 부위에 서 혀돌기 아래 $0.8 \mathrm{~cm}$ 까지 볼신경이 지나갈 수 있으므로, 어금니뒤삼각을 포함하여 교합평면에서 뒤쪽으로 연장선 
을 그어 그보다 위쪽의 턱뼈가지 부위에서 치료 시 볼신 경을 포함하여 관자근 힘줄도 손상 가능성이 있어 주의가 필요하겠다.

\section{감사의 글}

이 논문은 2015학년도 조선대학교 학술연구비의 지원을 받아 연구되었음.

\section{Conflict of Interest}

The authors declare that they have no competing interests.

\section{ORCID}

$\begin{array}{ll}\text { Heung-Joong Kim } & 0000-0003-1636-3669 \\ \text { Byung Soo Park } & 0000-0002-2908-3722 \\ \text { Yonghwa Cho } & 0000-0001-8053-8289 \\ \text { Sun-Kyoung Yu } & 0000-0003-0801-1663\end{array}$

\section{References}

1. Kim MK. Head and Neck Anatomy. 6th ed. Seoul: Dental \& Medical Publishing; 2017.

2. Drake R, Vogl AW, Mitchell AW. Anatomy for students. 2nd ed. London: Churchill Livingstone; 2009.

3. Yang HM, Won SY, Lee JC, Han SH, Kim HJ, Hu KS. Sihler-stain study of buccal nerve distribution and its clinical implications. Oral And Maxillofaial Surgery 2012;113:334-
339. doi: 10.1016/j.tripleo.2011.03.031.

4. Gerrs C, Nyssesn Behets C, Cosnard G, Lengele B. The deep belly of the temporalis muscle: an anatomical, histological and MRI study. Surg Radiol Anat 2005;57:184191. doi: 10.1007/s00276-004-0306-3.

5. Heady C, Smith K, Robinson P. Surgical anatomy of the buccal nerve. Br J Oral Maxillofac Surg 1996;34:457460. doi: 10.1016/S0266-4356(96)90108-4.

6. Merrill RG. Prevention, treatment, and prognosis for nerve injury related to the difficult impaction. Dent Clin North Am 1979;3:471-488.

7. Benninger B, Lee BI. Clinical importance of morphology and nomenclature of distal attachment of temporalis tendon. J Oral and Maxillofac Surg 2012;70:557-561. doi: 10.1016/j,joms.2011.02.047.

8. Schon Ybarra MA, Bauer B. Medial Portion of M. Temporalis and its potential involvement in facial pain. Clin Anat 2001;14:25-30. doi: 10.1002/1098-2535.

9. Merida Velasco JR, Rodriquez Vazquez JF, De La Cuadra C, Merida Velasco JA, Jimenez Collade J. The course of the buccal nerve: relationship with the temporalis muscle during the prenatal period. J. Anat 2001; 198:423-429. doi: 10.1046/j.1469-7580.2001.19840423.x.

10. Khoury JN, Mihailidis S, Ghabriel M, Townsend G. Applied anatomy of the pterygomandibular space: improving the success of inferior alveolar nerve block. Aust Dent J 2011;56:112-121. doi: 10.1111/j.1834-7819.2011.01312.x.

11. Ossenberg NS. Retromolar foramen of the human mandible. Am J Phys Anthropol 1987;73:119-128. dol: 10.1002/ ajpa.1330730112.

12. Takezawa K, Ghabriel M, Townsend G. The course and distribution of the buccal nerve: clinical relevance in dentistry. Aust Dent J Forthcoming 2017. doi: 10.1111/ adj: 12543 .

13. Harn SD, Sjackelford LS. Further evaluation of the superficial and deep tendons of the human temporalis muscle. Anat Rec 1982;202:537-548. doi: 10.1002/ar.1092020413. 